\title{
Arg389Gly $\beta 1$-adrenergic receptor polymorphism and susceptibility to syncope during tilt test
}

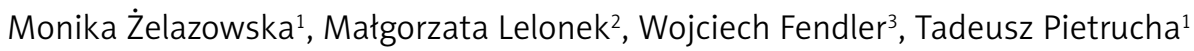

\author{
${ }^{1}$ Department of Medical Biotechnology, Medical University of Lodz, Poland \\ ${ }^{2}$ Department of Cardiology, Medical University of Lodz, Poland \\ ${ }^{3}$ Department of Paediatrics, Oncology, Haematology and Diabetology, \\ Medical University of Lodz, Poland
}

Submitted: 24 August 2011

Accepted: 2 January 2012

Arch Med Sci 2014; 10, 2: 240-245

DOI: $10.5114 /$ aoms.2014.42576

Copyright $\odot 2014$ Termedia \& Banach

\section{Abstract}

Introduction: Numerous hormones, neurotransmitters, and other stimuli exert their biological effect on cellular functioning through heptahelical receptors coupled to G proteins (GPCR - G protein-coupled receptors). Adrenergic receptors that belong to this superfamily of receptors are components of the sympathetic nervous system. They play a pivotal role in blood pressure regulation and myocardial contractility. Alterations of the adrenergic receptor pathway have been suggested to be involved in the pathophysiology of vasovagal syncope (VVS). The aim of the present study was to evaluate the distribution of Arg389Gly polymorphism within the ADRB1 gene among patients with recurrent syncope.

Material and methods: Arg389Gly single nucleotide polymorphism was analyzed in 205 patients with recurrent syncope. Ninety-five patients (46\%) had a positive head-up tilt test (HUT) result. The control group comprised 143 nonfainting subjects. Genotyping was performed by restriction fragment length polymorphism (RFLP) with BstNI enzyme.

Results: Both analyzed groups had similar distribution of the $389 \mathrm{Gly}$ allele. Sixty percent of polymorphic $389 \mathrm{Gly}$ carriers belong to the group of syncopal patients, while $40 \%$ belong to the control group of healthy subjects.

Conclusions: An association between syncopal incidence and Arg389Gly polymorphism within the ADRB1 gene was not found. The analyzed polymorphism affecting sympathetic activity does not influence vasovagal syncope in Polish patients.

Key words: syncope, genetic polymorphism, Tilt test, adrenergic receptors.

\section{Introduction}

Syncope is considered as a common and potentially dangerous clinical problem [1]. Vasovagal syncope (VVS) is one the most frequently observed types of this ailment [2,3]. The principal pathophysiological mechanism that underlies VVS is an abnormal, excessive reaction of cardiac mechanoreceptors that leads to hypotonia and/or bradycardia. Overstimulation of the autonomic nervous system that precedes syncope may be a result of alterations of cardiac adrenergic receptors' (AR) structure and/or function. The Arg389Gly polymorphism of the $\beta 1$-AR gene (ADRB1) is a functionally important alteration, associated with lower stimulation of adenylyl cyclase activity [4]. Moreover, this polymorphism was previously linked to
Corresponding author: Monika Żelazowska MD Department of Medical Biotechnology Medical University of Lodz 7/9 Zeligowski St 90-752 Lodz, Poland Phone: +48 507674185 E-mail: monika.zelazow@ gmail.com 
a positive result of the head-up tilt test (HUT) [5] in the Mexican population. The results however are not unanimous, as Sorrentino et al. [6] have shown that the Arg389Gly genetic variant should not be considered as a risk factor for vasovagal syncope in the Italian population.

The objective of this report was to determine the distribution of Arg389Gly polymorphism in the $\beta 1-A R$ gene among Polish patients with recurrent syncope who were examined by HUT.

\section{Material and methods}

\section{Study population}

The study population consisted of 205 adult patients suffering from syncope and free of any other diseases diagnosed in the Department of Cardiology at the Medical University of Lodz. Exclusion criteria were as follows: ECG abnormalities, positive family history of sudden cardiac death, syncope due to cardiac disease. Patients were tilted according to the Italian protocol $[7,8]$. The second group of analyzed subjects was composed of 143 healthy volunteers without any prior incidents of syncope. The clinical and demographic characteristics of study and control groups are presented in Table I. The study was approved by the Local Bioethics Committee and the patients' informed consent was obtained in all cases prior to any interventions related to the study protocol.

\section{Tilt test protocol}

The HUT according to the Italian protocol was performed using the tilt table SP-1 with a foot support and straps as described previously [7, 8]. Continuous ECG-curve registration was performed using a cardiomonitor and a 3-lead digital ECG recorder. Blood pressure, respiration rate and blood saturation were measured using a pulse oximeter throughout the HUT according to the protocol. The HUT consisted of a 20-min supine pre-tilt phase and a passive phase with the patient tilted upright to $60^{\circ}$. This passive phase of the Italian protocol was maintained for $20 \mathrm{~min}$. If syncope did not occur during the passive phase, $400 \mu \mathrm{g}$ of sublingual nitroglycerine in spray was administered in the upright position. The drug challenge phase was maintained for $20 \mathrm{~min}$. Syncope of patients with positive HUT was classified on the basis of the modified Vasovagal Syncope International Study (VASIS) classification as:

a) VASIS 1 (mixed),

b) VASIS 2 A (cardioinhibition without asystole),

c) VASIS 2 B (cardioinhibition with asystole),

d) VASIS 3 (vasodepressive).

Similarly to earlier studies by the authors [9], due to the small number of patients in VASIS $2 \mathrm{~A}$ and $B$ subgroups, both types were analyzed jointly. For statistical calculations, VASIS 1 and VASIS 3 were grouped together to be compared with VASIS 2.

\section{Analysis of Arg389Gly polymorphism}

Genomic DNA was isolated from peripheral blood drawn from the patients to EDTA-coated vials using the Chemagic DNA Blood100 kit (Chemagen, Baesweiler, Germany). The Arg389Gly polymorphism genotype (rs1801253) was detected using the restriction fragment length polymorphism (RFLP) method. The DNA fragment was amplified using site-specific oligonucleotide primers spanning the rs1801253 polymorphic site: P1: 5'-TGGGCTACGCCAACTCGG-3' and P2: 5'-GGCCCCGACGACATCGTC-3'. The polymerasechain reaction ( $P C R)$ was performed in the final volume of $25 \mu \mathrm{l}$ containing $1 \mu \mathrm{M}$ of $\mathrm{MgCl}_{2}, 0.2 \mathrm{mM}$ of equimolar deoxynucleotide mix, $0.8 \mu \mathrm{M}$ of each primer and 5\% dimethyl sulfoxide. An initial denaturation step $\left(94^{\circ} \mathrm{C}\right.$ for 5 min) was followed by thirty cycles of: denaturation $\left(94^{\circ} \mathrm{C}\right.$ for $1 \mathrm{~min})$, annealing $\left(59^{\circ} \mathrm{C}\right.$ for $\left.1 \mathrm{~min}\right)$ and an extension phase $\left(72^{\circ} \mathrm{C}\right.$ for $\left.1 \mathrm{~min}\right)$. Final extension was performed at $72^{\circ} \mathrm{C}$ for $8 \mathrm{~min}$. Digestion of

Table I. General characteristics of study and control group

\begin{tabular}{|lccc|}
\hline Parameter & Control & \multicolumn{2}{c|}{ Fainting } \\
\cline { 3 - 4 } & & Negative HUT & Positive HUT \\
\hline Number of patients & 143 & 110 & 95 \\
\hline Mean age [years] & 26 & 41 & 42 \\
\hline Males, $n(\%)$ & $77(54)$ & $37(34)$ & $37(39)$ \\
\hline BMI, mean \pm SD $\left[\mathrm{kg} / \mathrm{m}^{2}\right]$ & $22.32 \pm 2.17$ & $25.00 \pm 4.28$ & $25.10 \pm 4.37$ \\
\hline Systolic blood pressure at rest, mean \pm SD $[\mathrm{mm} \mathrm{Hg}]$ & - & $132.8 \pm 18.2$ & $126.8 \pm 14.7$ \\
\hline Diastolic blood pressure at rest, mean \pm SD $[\mathrm{mm} \mathrm{Hg}]$ & - & $83.5 \pm 12.1$ & $81.0 \pm 10.4$ \\
\hline Heart rate at rest, mean \pm SD [bpm] & - & $68.5 \pm 12.2$ & $68.0 \pm 13.7$ \\
\hline Saturation at rest, mean \pm SD $(\%)$ & - & $97.4 \pm 1.2$ & $97.7 \pm 1.3$ \\
\hline
\end{tabular}




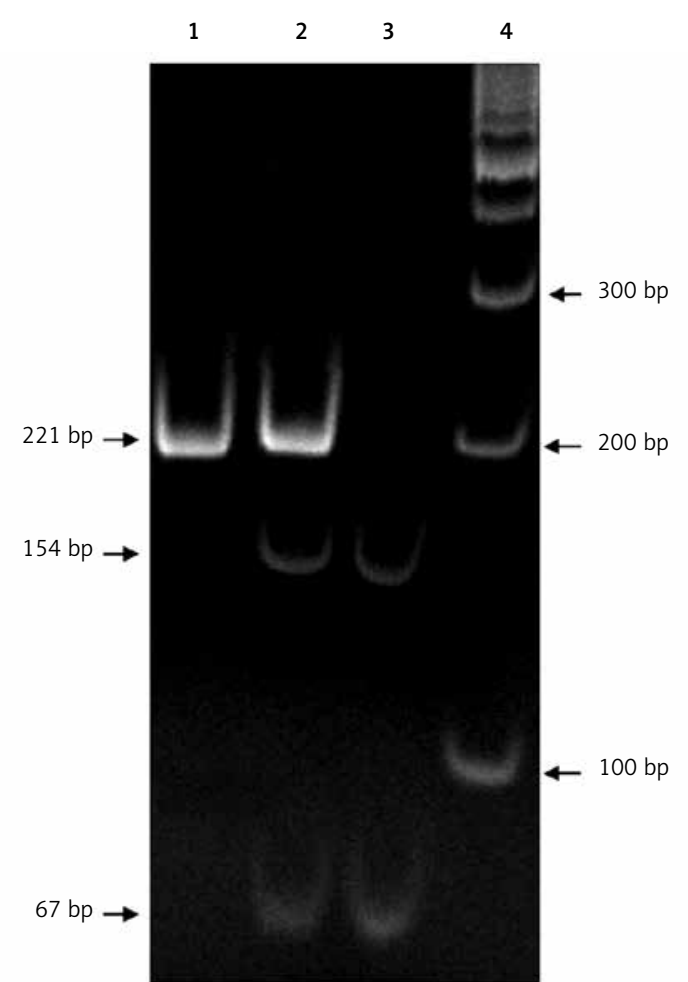

Figure 1. Genotyping results for Arg389Gly polymorphism of $\beta 1$-adrenergic receptor gene. Shown is pattern of bands on ethidium bromide-stained gel electrophoresis after BstNI digestion of PCR product. Lane 1, homozygous Arg/Arg; Lane 2, heterozygous Arg/Gly; Lane 3, homozygous Gly/Gly; Lane 4, GeneRuler $^{\mathrm{TM}} 100$ bp DNA Ladder (Fermentas). The position and size of bands are indicated by arrows

the 221-bp PCR product with restriction enzyme BstNI (New England Biolabs, Ipswich, UK) yielded a 221-bp product for Arg/Arg genotype, three (221-, 154- and 67-bp) products for heterozygous Arg/Gly genotype and two (154- and 67-bp) products for Gly/Gly homozygotes. Digested fragments were scrutinized on $40 \%$ polyacrylamide gel and visualized under UV light after ethidium bromide staining (Figure 1).

\section{Statistical analysis}

As a measure of association odds ratios (ORs) with $95 \%$ confidence interval $(95 \% \mathrm{Cl})$ were used.

Table II. Genotype distribution of Arg389Gly polymorphism in patients with syncope and control group

\begin{tabular}{|lccc|}
\hline Group & \multicolumn{3}{c|}{ Genotype } \\
\cline { 2 - 4 } & AA & AG & GG \\
\hline Fainting & $110(59 \%)$ & $82(59 \%)$ & $13(72 \%)$ \\
\hline Negative HUT & $53(28 \%)$ & $49(35 \%)$ & $8(44 \%)$ \\
\hline Positive HUT & $57(31 \%)$ & $33(24 \%)$ & $5(28 \%)$ \\
\hline Control & $77(41 \%)$ & $58(41 \%)$ & $5(28 \%)$ \\
\hline
\end{tabular}

$p=0.52$ for all fainting patients and control group; $p=0.37$ for negative HUT, positive HUT and control group
The $\chi^{2}$ tests were performed to test for deviations from the Hardy-Weinberg equilibrium. Categorical variables were compared using the Pearson's $\chi^{2}$ test or Fisher's exact test, depending on the number of observations and variables. Statistica version 8.0 PL (StatSoft Inc., Tulsa, USA) was used for data analysis. Values of $p<0.05$ were considered as statistically significant.

\section{Results}

Mean age of fainting patients in the study group was $41.5 \pm 15.7$ year; $36 \%$ were males. Ninety-five patients (46\%) had positive HUT: 21 during the passive phase and 65 during nitroglycerine administration. VASIS 1 response was observed in 63 patients, VASIS 2 response in 10 and VASIS 3 response in 19. Negative result of HUT was observed in a group of 110 patients (54\%). The control group comprised 143 patients (54\% males) (Table I); mean age equalled $28.7 \pm 12.00$ years (22.0-30.0). The control group was significantly younger than the study group ( $p<0.0001)$. Sex distribution differed significantly due to a greater percentage of males in the control group $(p=0.003)$.

The frequencies of Arg389Gly genotypes in the control group did not show significant deviations from the Hardy-Weinberg equilibrium ( $p=0.13$ ). The distribution of all genotypes is presented in Table II. No significant differences were observed between the study and control group ( $p=0.52$ ). Allele distributions in the control group and syncopal patients were very similar $(p=0.81)$. Carriers of the polymorphic $389 \mathrm{Gly}$ allele were present in both groups and were distributed similarly in both groups. Therefore the carriage of the polymorphic allele did not increase the odds of syncope (OR = 1.06, 95\% Cl: 0.69-1.63) (Table III). An association between carriage of this allele and negative result of the tilt test in the group of patients with syncope was observed, but did not reach statistical significance ( $p=0.09$; Table III). There was no association between the VASIS classification type of positive tilt response and genotype $(p=0.76)$ or polymorphic $389 \mathrm{Gly}$ allele carriage $(p=1.00)$.

Table III. Distribution of alleles in patients with syncope and control group

\begin{tabular}{|lcc|}
\hline Group & \multicolumn{2}{c|}{ Genotype } \\
\cline { 2 - 3 } & Arg/Arg & Gly+ \\
\hline Fainting & $110(59 \%)$ & $95(60 \%)$ \\
\hline Negative HUT & $53(28 \%)$ & $57(36 \%)$ \\
\hline Positive HUT & $57(30 \%)$ & $38(24 \%)$ \\
\hline Control & $77(41 \%)$ & $63(40 \%)$ \\
\hline $\begin{array}{l}p=0.23 \text { for negative HUT, positive HUT and control group; } \\
p=0.81 \text { for all fainting patients and control group }\end{array}$
\end{tabular}




\section{Discussion}

Numerous recent studies support the hypothesis that vasovagal syncope may be in fact a disease of strong genetic background [10]. Still, the association of various genetic variations with VVS is not as evident as initially expected, due to the limited number of relevant research papers focused on the matter [11] and further overshadowed by small sample sizes. In a study of French patients with unexplained syncope, a strong association between syncopal incidence, positive HUT and CC variant in the adenosine $A_{2 A}$ receptor $\left(A D O R A_{2 A}\right)$ gene was found [12]. Recently, Sorrentino and Forleo et al. investigated the $3 A / 4 A$ polymorphism of the endothelin-1 gene (EDN1). A strong association between $4 \mathrm{~A}$ variant carriage and susceptibility to syncope was elucidated [13]. In a group of Polish patients with syncopal events, polymorphic variants of GNAS1, GNB3 and RGS2 were examined and showed mixed effects [7, 9, 14-17]. Although the molecular mechanism of VVS is still under investigation, preliminary results of aforementioned studies are promising.

Genetic alterations in the sympathetic system may be involved in pathophysiological mechanisms leading to VVS. Signal transduction pathway $\beta 1$-adrenergic receptors regulate critical aspects of heart muscle contractility and blood pressure control [18]. They mediate the actions of two neurotransmitters (noradrenaline and adrenaline) through activation of heterotrimeric $G$ proteins, and belong to the $G$ protein-coupled receptor (GPCR) family. In vertebrates, this family of proteins contains from 1000 to 3000 members coded by genes that comprise $1-3 \%$ of the whole genome [19]. The GPCRs are built of seven transmembrane $\alpha$-helices that are buried in cellular membrane preceded by an extracellular $\mathrm{N}$-terminal domain and followed by an intracellular C-terminal domain [20]. The studied Arg to Gly polymorphism at position 389 of $\beta 1-A R$ is located close to the carboxyl terminus that is predicted to be an $\alpha$-helix located on the cytoplasmic site of the cellular membrane. This region is evolutionally conserved as it is ubiquitous for $G_{s}$ protein interaction [4, 21, 22]. Arg389Gly variants respond differently to catecholamine treatment [23]. The Arg variant exhibits increased responsiveness to agonist-induced stimulation in vitro [24] while the Gly variant is believed to disrupt $\alpha$-helical structure of the region and lead to reduced responsiveness [25]. Moreover, Arg389Gly polymorphism may influence the GRK-dependent desensitization process [26]. The study of Rathz et al. revealed that desensitization for the Arg389 variant was in fact $50 \%$ greater than that of the $389 \mathrm{Gly}$ genotype [27].

The distribution of Arg389Gly polymorphism was reported in dbSNP. According to data gathered in this database, the frequencies of Arg389 and 389Gly alleles in the Caucasian population are equal to 0.68 and 0.32 , respectively. The OMIM database gives the frequencies of 0.74 and 0.26 for Arg389 and 389Gly alleles, respectively. In our study, the proportion of genetic variants is similar and in line with data of healthy subjects (Table IV).

So far, the main limitation of conducted studies is the lack of a control group composed of a normative population representative of non-fainting subjects. In the present report, a group of 143 healthy volunteers was enrolled and genotyped. The distribution of Arg389Gly variants of the $A D R B 1$ gene in controls was close to HapMap data (0.76 for Arg389 variant and 0.24 for 389Gly variant; for further data see Table IV). A limiting factor

Table IV. Allele frequencies of Arg389Gly polymorphism in ADRB1 gene in different populations

\begin{tabular}{|c|c|c|c|c|}
\hline \multirow[t]{2}{*}{ Population } & \multirow[t]{2}{*}{ Number of subjects } & \multicolumn{2}{|c|}{ Allele frequency } & \multirow[t]{2}{*}{ Reference } \\
\hline & & Arg & Gly & \\
\hline Non-fainting subjects & 143 & 0.760 & 0.240 & Present study \\
\hline Syncopal patients with negative HUT & 110 & 0.700 & 0.300 & \\
\hline Syncopal patients with positive HUT & 95 & 0.770 & 0.230 & \\
\hline HapMap CEU ss38568848 & 60 & 0.683 & 0.317 & [32] \\
\hline OMIM & 50 & 0.740 & 0.260 & {$[32,33]$} \\
\hline US White & 316 & 0.720 & 0.280 & [34] \\
\hline Syncopal patients with negative HUT & 17 & 0.970 & 0.030 & [6] \\
\hline Syncopal patients with positive HUT & 33 & 0.697 & 0.303 & \\
\hline All syncopal patients & 129 & 0.690 & 0.310 & [7] \\
\hline Syncopal patients with negative HUT & 56 & 0.660 & 0.340 & \\
\hline Syncopal patients with positive HUT & 73 & 0.710 & 0.290 & \\
\hline
\end{tabular}


here may be the significant age difference, as controls were younger than fainting patients. Taking into consideration the fact that the effect of a genetic polymorphism does not generally increase during an individual's lifetime and vasovagal syncope manifests mainly at early age [1], selection of the control group seems to be proper despite the age difference.

Marquez et al. [4] showed that in patients of Mexican origin the Arg389Gly polymorphism may be associated with susceptibility to fainting. The 389Gly variant was found to be more frequent in patients with syncope and positive HUT (30.3\%) in comparison with fainters with negative HUT (3\%). Marquez stated that a decreased inotropic response of the Gly allele may alter adrenergic stimulation that takes place during orthostatic challenge. However, the distribution of the 389Gly allele in the positive HUT group is similar to that in the general healthy population of Caucasian descent (Table IV). The 389Gly variant is likely to be important as a key determinant of susceptibility to fainting during HUT, but cannot be considered as a main risk factor of vasovagal syncope.

Sorrentino et al. [6] in a cohort of Italian patients did not find evidence for a genetic background of vasovagal syncope. In this study, a broad range of genetic polymorphisms affecting sympathetic activity were scrutinized, i.e. Arg492Cys (ADRA1A gene), Ser49Gly and Arg389Gly (ADRB1), Arg16Gly and Gln27Glu (ADRB2), 825C/T (GNB3), -1021C/T $(\mathrm{DBH})$ and $\mathrm{S} / \mathrm{L}$ (SLC6A4). None of them seemed to influence the result of positive HUT.

Previous studies demonstrated that vasovagal syncope is more frequent in females than in males $(42 \%$ vs. $31 \%)[28,29]$. However, in the aforementioned study the individuals were diagnosed exclusively based on their questionnaire without performing HUT or other medical investigations. Thus, females are more susceptible to fainting and/or are more likely to volunteer the information than males. In the group of fainting patients the result of HUT does not depend on gender as shown by Pietrucha et al. [30] but females experience syncopal incidents for longer periods of their lives [31]. In the present report, the male population was overrepresented in the control group ( $54 \%$ in control vs. $36 \%$ in study group). This parameter may slightly influence the results of the research, but there is no strong scientific evidence that susceptibility to vasovagal syncope depends on gender.

The main limitation of the present study was the small number of healthy subjects enrolled in the control group. Due to the low abundance of homozygotes for the Gly allele and small sample size, the results should be confirmed in a larger population.
In conclusion, an association between syncopal incidence and Arg389Gly polymorphism within the ADRB1 gene was not found. The analyzed polymorphism affecting sympathetic activity does not influence tilt-induced vasovagal syncope in Polish patients.

\section{Acknowledgments}

Supported by the Medical University of Lodz, grant no. 502-19-859.

Wojciech Fendler has received financial support from the TEAM project of the Innovative Economy Operational Programme of the European Union and Foundation for Polish Science.

\section{References}

1. Moya A, Sutton R, Ammirati F, et al. Guidelines for the diagnosis and management of syncope (version 2009): the Task Force for the Diagnosis and Management of Syncope of the European Society of Cardiology (ESC). Eur Heart J 2009; 30: 2631-71.

2. Jhanjee R, Can I, Benditt DG. Syncope. Dis Mon 2009; 55: $532-85$.

3. Chen L, Wang C, Wang H, et al. Underlying diseases in syncope of children in China. Med Sci Monit 2011; 17: H49-53.

4. Small KM, McGraw DW, Liggett SB. Pharmacology and physiology of human adrenergic receptor polymorphisms. Annu Rev Pharmacol Toxicol 2003; 43: 381-411.

5. Marquez MF, Hernandez-Pacheco G, Hermosillo AG, Gomez JR, Cardenas M, Vargas-Alarcon G. The Arg389Gly beta1-adrenergic receptor gene polymorphism and susceptibility to faint during head-up tilt test. Europace 2007; 9: 585-8.

6. Sorrentino S, Forleo C, lacoviello M, Guida P, D'Andria V, Favale S. Lack of association between genetic polymorphisms affecting sympathetic activity and tilt-induced vasovagal syncope. Auton Neurosci 2010; 155: 98-103.

7. Lelonek M, Pietrucha T, Matyjaszczyk M, Goch JH. Mutation T/C, lle 131 of the gene encoding the alfa subunit of the human Gs protein and predisposition to vasovagal syncope. Circ J 2008; 72: 558-62.

8. Del RA, Bartoli P, Bartoletti A et al. Shortened head-up tilt testing potentiated with sublingual nitroglycerin in patients with unexplained syncope. Am Heart J 1998; 135: 564-70.

9. Lelonek M, Pietrucha T, Matyjaszczyk M, Goch JH. A novel approach to syncopal patients: association analysis of polymorphisms in G-protein genes and tilt outcome. Europace 2009; 11: 89-93.

10. Bizios AS, Sheldon RS. Vasovagal syncope: state or trait? Curr Opin Cardiol 2009; 24: 68-73.

11. Olde Nordkamp LR, Wieling W, Zwinderman AH, Wilde AA, van Dijk N. Genetic aspects of vasovagal syncope: a systematic review of current evidence. Europace 2009; 11: 414-20.

12. Saadjian AY, Gerolami V, Giorgi R, et al. Head-up tilt induced syncope and adenosine A2A receptor gene polymorphism. Eur Heart J 2009; 30: 1510-5.

13. Sorrentino S, Forleo C, lacoviello M, Guida P, D’Andria V, Favale S. Endothelin system polymorphisms in tilt test-induced vasovagal syncope. Clin Auton Res 2009; 19: 347-54. 
14. Lelonek M, Pietrucha T, Matyjaszczyk M, Goch JH. Genetic insight into syncopal tilted population with severe clinical presentation. Auton Neurosci 2009; 147: 97-100.

15. Lelonek M, Pietrucha T, Matyjaszczyk M, Goch JH. Polymorphism C1114G of gene encoding the cardiac regulator of G-protein signaling 2 may be associated with number of episodes of neurally mediated syncope. Arch Med Res 2009; 40: 191-5.

16. Huang YJ, Bao LM, Wang JY, Huang M. Association be tween the polymorphism of GNB3 C825T gene and vasovagal syncope in children [Chinese]. Zhonghua $\mathrm{Er} \mathrm{Ke}$ Za Zhi 2010; 48: 896-9.

17. Lelonek M, Zelazowska M, Pietrucha T. Genetic variation in Gsalpha protein as a new indicator in screening test for vasovagal syncope. Circ J 2011; 75: 2182-6.

18. Dzimiri N. Receptor crosstalk. Implications for cardiovascular function, disease and therapy. Eur J Biochem 2002; 269: 4713-30.

19. Bockaert J, Pin JP. Molecular tinkering of G protein-coupled receptors: an evolutionary success. EMBO J 1999 18: 1723-9.

20. Bockaert J. G Protein-coupled recptors. Encyclopedia of Life Sciences 2009.

21. Liggett SB, Mialet-Perez J, Thaneemit-Chen S, et al. A polymorphism within a conserved beta(1)-adrenergic receptor motif alters cardiac function and beta-blocker response in human heart failure. Proc Natl Acad Sci U S A 2006; 103: 11288-93.

22. Dorn GW, Liggett SB. Mechanisms of pharmacogenomic effects of genetic variation within the cardiac adrenergic network in heart failure. Mol Pharmacol 2009; 76: 466-80.

23. La RK, Huntgeburth M, Rosenkranz S, Bohm M, Schnabel P. The Arg389Gly beta1-adrenoceptor gene polymorphism determines contractile response to catecholamines. Pharmacogenetics 2004; 14: 711-6.

24. Mialet PJ, Rathz DA, Petrashevskaya NN, et al. beta1-adrenergic receptor polymorphisms confer differential function and predisposition to heart failure. Nat Med 2003; 9: 1300-5.

25. Liggett SB. Polymorphisms of adrenergic receptors: variations on a theme. Assay Drug Dev Technol 2003; 1 : 317-26.

26. Bojic T, Sudar E, Mikhailidis D, Alavantic D, Isenovic E. The role of $G$ protein coupled receptor kinases in neurocardiovascular pathophysiology. Arch Med Sci 2012; 8: 970-7.

27. Rathz DA, Gregory KN, Fang Y, Brown KN. Hierarchy of polymorphic variation and desensitization permutations relative to beta1- and beta2-adrenergic receptor signaling. J Biol Chem 2003; 278: 10784-9.

28. Serletis A, Rose S, Sheldon AG, Sheldon RS. Vasovagal syncope in medical students and their first-degree relatives. Eur Heart J 2006; 27: 1965-70.

29. Ganzeboom KS, Colman N, Reitsma JB, Shen WK, Wieling W. Prevalence and triggers of syncope in medical students. Am J Cardiol 2003; 91: 1006-8.

30. Pietrucha A, Wojewódka-Zak E, Wnuk M, et al. The effects of gender and test protocol on the results of headup tilt test in patients with vasovagal syncope. Kardiol Pol 2009; 67: 1029-34.

31. Park J, Jang SY, Yim HR, et al. Gender difference in patients with recurrent neurally mediated syncope. Yonsei Med J 2010; 51: 499-503.

32. Sherry ST, Ward MH, Kholodov M, et al. dbSNP: the NCBI database of genetic variation. Nucleic Acids Res 2001; 29: 308-11.
33. Mason DA, Moore JD, Green SA, Ligget SB. A gain-offunction polymorphism in a G-protein coupling domain of the human beta1-adrenergic receptor. J Biol Chem 1999; 274: 12670.

34. Xie HG. Arg389Gly beta1-adrenoceptor polymorphism varies in frequency among different ethnic groups but does not alter response in vivo. Pharmacogenetics 2001; 11: 191-7. 